Article

\title{
Information Pluralism and Some Informative Modes of Ignorance
}

\section{Erkki Patokorpi}

IAMSR, Abo Akademi University, Joukahaisgatan 3-5A, 20520 Abo, Finland;

E-Mail: epatokor@abo.fi

Received: 11 November 2010 / Accepted: 11 January 2011 / Published: 17 January 2011

\begin{abstract}
In this paper information concepts will be roughly divided into two categories: The cybernetic and the semiotic-pragmatic. They are further divided into three and four subcategories, respectively. The cybernetic conception of information, which comprises both the mathematical-statistic and the logical-semantic approaches, misses some aspects of information and knowing, that are important in economics and technology studies, among others. The semiotic-pragmatic approach presumes the existence of several modes of being of information, as well as connects certainty and ambiguity to information in a different way from how the cybernetic approach does. These two general approaches to information and knowing are strikingly different, especially in their analysis of ignorance or incomplete knowledge. None of the cybernetic conceptions, and only some conceptions within the semiotic-pragmatic approach, can vindicate the elusive intuition of the potential positive role of ignorance. This comparative, philosophical discussion of the modes of ignorance may be taken as a challenge for cybernetics and computational philosophy to make better sense of incomplete knowledge.
\end{abstract}

Keywords: ignorance; information; ecological rationality; abduction; bounded rationality; heuristics; cybernetics

\section{Introduction}

Various scholars have criticized the mathematically and systemically based understanding of information, pointing out shortcomings and suggesting expansions or alternatives. For instance, Milan Zeleny [1] has analyzed the dynamics of emergence of higher-level processes from lower-level processes of information, from data to wisdom. Luciano Floridi [2] has identified different, alternative 
ontological conceptions of information. Armand Hatchuel [3], Milan Zeleny [4] and Bryan Caplan [5] have criticized the impoverishing impact of a mathematical-statistic model of information on economic analysis. Gerd Gigerenzer [6] has pointed out the positive effects of a lack of information for reasoning and decision making in real life, which is an aspect of information that escapes more abstract approaches. Building on the work of these writers, among others, a step further will be taken here in an attempt to analyze and criticize the cybernetic conception of information, and to do so especially by comparing it, or rather instances of it, with a number of other conceptual arguments and approaches that arguably are more successful. What is here labeled the cybernetic conception comprises both the mathematical-statistic understanding of information based on Shannon's theory and the so-called logical-semantic conception of information.

It should be borne in mind that this is about Earth informations. As Newtonian physics applies just fine for the physics we experience in our life, we need not take into account how information behaves at different points in time of the evolution of the cosmos or at the level of subatomic particles. Here an anthropocentric, or rather sentient-centric, point of view is not a fallacy because, insofar as non-cybernetic conceptions of information and knowledge are concerned, experiential phenomena will be in focus.

The paper starts off with a brief description of the mainstream, cybernetic conception of information. The next section introduces Zeleny's information/knowledge hierarchy. The information/knowledge hierarchy helps keeping track of the concepts of data, information and knowledge, which often tend to get mixed up. A decisive step in the conceptual expansion beyond the cybernetic conception attempted here is to assume a pluralistic conception of information, which will be the subject of the third section. This step involves examining both the ontological and epistemic character of the basic forms of information, or, in brief, informations. Three diverse ontological levels of information will be distinguished. It means that they are all real, notwithstanding that they do not exist in the same manner. Sections on certainty and vagueness aim to lay bare in how fundamentally different ways these concepts can be connected to information. The following four sections analyze, one by one, different modes of insufficient knowledge or ignorance. It will be done in accordance with a rough division of information concepts into two categories: The cybernetic and the semiotic-pragmatic. The remaining section before the conclusion summarizes the various conceptualizations of information discussed in this paper.

Nobody denies the successes of the cybernetic and computational approaches to information, but it is equally true that few, if anyone, would claim that the cybernetic view on information is all-encompassing. The contribution of this paper is not so much to point out the inadequacy (no quarrel there) of the cybernetic view, but to do so from an interesting perspective in a philosophically interesting, and hopefully, in a scientifically fruitful way. Instead of focusing on issues like false information and misinformation, as is common in information science and computational philosophy, the present paper focuses on ignorance. Ignorance brings out a number of more or less systematic differences between different conceptions of information and knowledge, the most prominent dividing line being the one between cybernetic and semiotic-pragmatic conceptions. The way in which information and ignorance will be discussed can be characterized as cross-disciplinary and philosophical. It means among other things that the argumentation keeps as close to the everyday language as possible and makes things intelligible through examples. 
The selection of concepts under the label of semiotic-pragmatic, includes both semiotic and pragmatic approaches as well as mixtures of both (e.g., abduction). The aforementioned concepts are semiotic due to their giving primacy to the community of sign interpreters, with the important additional move of not confining signs to symbolic signs alone. They are pragmatic in the broad sense that they presume systems to be open and capable of experience. The term semiotic-pragmatic will become clear-or at least clearer-through examples of information conceptions that are juxtaposed and compared with cybernetic conceptions of information. In this paper the selection of examples is such that "semiotic-pragmatic" equals "noncybernetic".

\section{A Cybernetic View on Information}

Claude Shannon's [7] mathematical-statistic theory of information has become part of modern folklore in spite of the fact that not all computer scientists, or IS researchers, have read his seminal article or the book co-authored with Weaver [8]. Only a few central ideas will be repeated here. A binary digit, or bit, for short, is the measure of information in a message. If the 1 and 0 are equally likely, the bit gives the maximum amount of information. If either 1 or 0 is perfectly predictable, the bit is redundant, giving no information. Entropy, which equals disorganization, measures the quantity of information. The more entropy the more bits are required for reliable communication. Consequently, much entropy translates into disorganization, which in turn translates into high uncertainty. Semantics (the meaning or quality of data) has no place in Shannon's theory: “These semantic aspects of communication are irrelevant to the engineering problem" [7] (p. 1/55). The theory considers the readability of data, though, which is measured by the calculation of probabilities.

Norbert Wiener [9] defines cybernetics as the study of the communication and control of both living organisms and machines. Organisms and machines, as well as organizations, are primarily conceived as information processors. Wiener's (1st edition 1948) [9] (p. 132) famous line "Information is information not matter or energy" posits information as reality, a mode of being in its own right. Wiener's feedback principle seeks to formalize (mechanize) the way organisms and social systems change their behavior in response to their surroundings so that it can be applied to all systems. The feedback loop is understood as a causal circular loop by which a goal-oriented system changes the environment, takes note via information of the change and changes its own behavior in response to the change in the environment. In other words, cybernetics studies the principles of control and self-regulation in all kinds of systems.

For the purposes of this paper, a cybernetic conception of information is here seen as including both Shannon's mathematical-statistic and Wiener's functional conceptions. Sometimes a so-called logical-semantic conception of information is introduced as a supplement to the cybernetic one. On this view, information encompasses all that can be logically inferred (deduced) from the information given. In the same way as an acorn is supposed to contain all the information required for it to become a full-grown oak, for instance the axioms of the Pythagorean geometry are supposed to contain all the theorems $[10,11]$. 


\section{Information/Knowledge Hierarchy}

The so-called DIKW (data, information, knowledge, wisdom) hierarchy traces the differences between levels from data to wisdom. Nowadays, information science professionals generally agree that the parts of DIK (W) form some sort of an ordered sequence, although their definitions of the parts differ [12]. Data is raw observations and measures; Uninterpreted differences. Data becomes information when structured (there is no information without order) and put into a context. Contextualization implies an audience and a purpose. Information put to use or interpreted is knowledge (e.g., a recipe for Peking Duck becomes knowledge when you cook the dish). Knowledge becomes wisdom when it is used to make choices. Instead of how (to act or interpret), one asks why and when. Wisdom entails value judgments, deciding between right and wrong [1,13]. With the exception of Zeleny [4], little attention is usually paid to Wisdom.

Tactical moves can be found out by asking how-questions, that is, questions of how something is done. In management this involves studies of tasks and how they could be improved. How-questions do not illuminate the ethical level, which is studied by asking why-questions [4]. It seems evident that in practical life we routinely make distinctions between knowledge and wisdom, which corresponds to the epistemic and ethical levels of discourse, respectively. We may for instance doubt that the decision by the United States to attack Iraq was made to ascertain access to oil, and hence purely a tactical move made in reply to a how-question. However, the fact that we do doubt it at all shows that the ethical level of knowledge or discourse exists, irrespective of whether people or groups act ethically or not.

Zeleny [4] poignantly criticizes the present mechanistic view on management and economics. Enterprises are seen as machines and the solutions to their problems are sought in techniques and concepts borrowed from the engineering sciences and cybernetics. Hatchuel [3] seems to be in agreement with Zeleny's line of criticism. He points out that an abstract, systemic view of information, which he calls the cybernetic information paradigm, has led to an inability to tell information and knowledge apart. In economics it has led to equating firms with information flows and abstract networks of information. A logical, but mistaken conclusion, is to picture entrepreneurship largely as an organizational problem of matching knowledge resources with information channels. Cybernetics blurs the line between the human and the machine. In the last analysis the human being and social systems are more or less complicated causal-mechanical feedback systems, that is, machines. In the words of Wiener and Rosenblueth: "as objects of scientific enquiry, humans do not differ from machines" (quoted in [14] (p. 251)). Zeleny (4), in contrast, regards enterprises and whole economies as organisms, stressing the point that biology rather than the engineering sciences is a better source of thinking tools for management sciences and economics in general.

However, DIK has been extensively criticized by various researchers [15-17]. The issue of the structure and dynamics of DIK is complicated, so I will discuss it only insofar as it is relevant to the division between cybernetic and noncybernetic conceptions of information. Let us focus on Tuomi's [15] influential reversal of DIK. According to Tuomi, there cannot be data (and information) before there is knowledge. Data cannot come into existence before it has been structured and related to something, that is, before there is information. Information cannot come into being before there is an interpreter, and eventually a community of interpreters, who interpret or make sense of the 
information. Interpreted information in turn is called knowledge. Hence, the traditional hierarchy of DIK should be reversed so that knowledge precedes information and information precedes data. Data is very much something that is made by sentient beings. In this sense "data is more than knowledge".

Tuomi's criticism is reminiscent of Zeno's paradox: Achilles (data) can never catch the tortoise (knowledge), which (i.e., knowledge) in Tuomi's reductio ad absurdum of DIK has a head start. Nevertheless, in real life Achilles does catch the tortoise, meaning that there cannot be data before information and knowledge. Turning DIK in this way upside down (KID) does not solve all problems. Firstly, the traditional idea of data (and information) preceding knowledge makes good, convincing common sense. It seems intuitively more reasonable to say that knowledge is something more than information, than to say that information is something more than knowledge. Secondly, Zeno's paradox seems to work the other way round equally well, and thus Zeleny's reductio ad absurdum of KID could look like this: Achilles (knowledge) cannot catch the tortoise (data), which (i.e., data) has a head start. Thus Tuomi's accusation can be countered by accusing KID of a similar logical blunder. Some important practical consequences follow. The reversed DIK hierarchy (KID) presents a static world; making it difficult to explain how radically new knowledge can emerge. The point in Zeno's original paradox was exactly to argue in favor of Parmenides' teachings that time and change are illusions. Another way of making sense of this static outlook on the world is to say that KID stresses knowledge creation by inductive-deductive processes, whereas DIK stresses an abductive, and thereby in some sense a more dynamic, approach to knowledge creation [18]. The reversed hierarchy, or KID, understandably appeals to many computer scientists and information systems professionals as it better supports fixing the meaning by well-defined semantics and ontologies for the purpose of storing it in databases [19]. DIK in turn stays more open to new data and to the creation of new meaning.

Clearly, and most importantly, the information/knowledge hierarchy works both ways: Sometimes knowledge is required for information to be structured and articulated, and some information exists outside of a knower, giving rise to knowledge (by a knower). Assuming that information pluralismwhich will be presented in the next section-is correct, one does not have to commit to the idea that no information exists outside of a knower [20]. I see this disagreement on the information/knowledge hierarchy as just another sign of the deep division between cybernetic and noncybernetic conceptions of information, although in this case the division is perhaps not as clear cut as in some of the following examples.

One problem related to the Data-Information-Knowledge hierarchy is that when one closely identifies knowledge with action, there is a danger of making knowledge into an epiphenomenon of action, as has been done by Dourish [21] and Patokorpi [19]. In this way an essential piece of the puzzle will be missed, namely, experience. Pragmatism, naturalism, grounded cognition, organicism, the bottom-up approach and emergentism do not necessarily have to lead to epiphenomenalism and determinism. In other words, thoughts and feelings, in a word, experience, can be seen to have an objective reality without having to reduce it to physics in order to do so. Although the mainstream empirical and experimental sciences have no grasp of experience-the qualitative, inner side of life which is directly accessible only to the organism itself-it does not mean that no such 'thing' would exist and that it therefore would have to be little more than an illusion, an epiphenomenon. Charles Sanders Peirce's [22] (pp. 6.280-6.284) pragmatic, indeterministic, non-mechanistic philosophy gives a coherent account of experience as an immanent (i.e., a real entity but not an existent) phenomenon 
that is not reducible to physical matter or events, although it is not in conflict with but, on the contrary, in harmony with physical laws and regularities. For instance, to borrow an example from biosemiotics, the biological level of being includes the physical-chemical level so that a living organism is simultaneously physical-chemical and biological $[23,24]$.

\section{Information Ontology}

Luciano Floridi $[2,25,26]$ distinguishes between three basic ontological views on information. The first one is the representational view of information, according to which all information is carried by signs. There is no information without representation by symbols or other signs. According to the second view, it is possible to have information without an interpreter or meaning or anything that extracts it. Information is neither physical nor mental but something separate from these, namely information. An example of information without sign representation is the year rings on a tree trunk. What this second ontological view expressly denies is that the year rings of the tree trunk represent anything. The year rings can be seen as order or form of some sort without an interpreter, and this order is not signs but information. The third ontological view regards information's mode of being as a threshold between the interpreter and the world. In other words, it is an interface. For instance, let us say that I am teaching someone to do a certain task on a computer. I try explaining it but cannot do so verbally but have to sit down by the computer and show how it is done. Information emerges when bodies, minds and objects (in this case a computer) interact.

These three basic ontological views on information seem to be in conflict with one another. For instance, if all information is in signs, there cannot be information out there without something (signs) that carries it [25]. However, all three could be partially true. Some information is in signs. Some information is out there, irrespective of a mind or an organism that could process it. And some information emerges when minds, bodies and objects meet. Consequently, information could be divided into representational, out-there and emergent. In contrast to the cybernetic view, information is here seen as having several basic forms of being. There is no conclusive evidence or argument to back up the claim of information pluralism, but as long as there respectively is no conclusive evidence or argument to prove that one of the forms of being of information is right (i.e., exists) and the others wrong (i.e., do not exist), the assumption of information pluralism seems reasonable.

Information pluralism helps us to account for some things about human knowing that a cybernetic view from nowhere does not. By the "view from nowhere" is meant an acontextual, ahistorical and disembodied view of knowing, typically accompanied by a total neglect of how the data is generated. In contrast, Mark Burgin [27] extends the traditional ontology of information, pointing out that there is both information without symbolic representation and uninterpreted data. Information is thus not carried by symbolic or sign representations alone but can be external to the mind. Burgin differentiates between influences to and from knowledge, thereby recognizing an ontological form of information that is in some sense out there. In other words, the nature of influence from the object to the sign (some sort of determination or causation) is different from that of sign to the object (representation). The exact nature of the influence (efficient cause, formal cause) and the nature of the carriers of information (dead matter, living matter, symbols, icons, analogue, digital) are important metaphysical issues but beyond the scope of this paper. The program of fast and frugal heuristics [6] (p. 58), among 
others, recognizes a representational information mode and an information structure of the environment, which entails an ontological distinction between information as representation by signs and information as something out there. Lorenzo Magnani’s [28,29] manipulative abduction, in turn, presumes an emergent mode of being of information. These are examples of information concepts that are, ontologically and otherwise, wider than the cybernetic one.

\section{Certainty}

The mainstream of epistemological thought traditionally connects information with certainty so that more information translates into greater certainty [30,31]. Information systems professionals and engineers are eager to interpret for instance organizational problems as problems of insufficient information because they have the technology to deal with that kind of problem. Technology in general tends to make all problems into problems of uncertainty, to be resolved by more information [32].

A related issue is how uncertainty is connected to complexity. Unlike in Shannon's theory, in Wiener's cybernetics complexity indicates a high degree of organization whereas disorganization equals uniformity, leading eventually to a cosmic heat death [9,33]. In bounded rationality high complexity is interpreted as an indicator of high uncertainty. Complex matters contain more information and when the amount of information exceeds the processing capacity of the system (e.g., the human brains), the result is uncertainty. Both complete and bounded rationality hold that given complete information - which they simply assume to be there - certainty will be achieved. In economics the advocates of complete rationality make no special connection between uncertainty and complexity. Certainty and uncertainty are purely subjective matters that do not reflect reality itself but only our cognitive capacity to know reality [34].

Since the Platonic Socrates, there is a strong historical counter current of thought that turns the relation between knowledge and certainty upside down. Socratic dialogues famously sought to expose how the most certain judgments were built on ignorance. In the same vein of thought, Karl Weick [32] argues that in many cases the problem is not too little information but confusion about what is the problem in the first place (i.e., equivocality or too many meanings). Confusion is resolved not through more information but by discussion or discursive means in general because there is no objective data as the whole issue is unclear. Not until clarity or agreement is achieved about the issue, the problem of equivocality will become a problem of uncertainty. Until clarity is achieved more information only increases uncertainty.

\section{Vagueness}

According to Congleton [35], the advocates of bounded rationality have paid little attention to cases where decision-makers restrict their information search into a subset of potentially available data. The resultant ignorance owes rather to informational constraints than any computational limitations. Informationally bounded decision-makers would make better decisions if they had expanded their information search from local to global data sets. For instance, if I were to search for the best price only in malls, leaving out discount stores, I would be likely to end up with a local optimum inferior to the global optimum. Although I am fully rational, I would be systematically wrong: "Only ignorance leads rational individuals to draw systematically mistaken conclusions about the world” [35] (p. 9). Increasing 
the sample at the same time provides new information and reduces certainty because a larger sample is likely to be more complex. Unlike the neoclassical theory - which is based on the idea of a finite, global, complete sample_-assumes, more information does not automatically increase certainty.

According to Peirce, life develops habits and therefore moves towards greater generality, that is, a greater general order of the world. The general is therefore more real than individuals [36]. We come to know the world through signs. All signs lack in clarity because we always can detect some new aspects in objects. Clarity and certainty are results of ignorance. The moment we detect a new aspect in objects, we come to realize that our earlier beliefs were vague. Vagueness is even more fundamental than generality [37]. Vagueness guarantees that we can always learn more, discover new aspects of objects. We detect a new aspect by way of a surprising fact (an anomaly). This triggers an abductive process of coming up with an explanation (hypothesis). Abduction thus often starts off or is triggered by recognized ignorance that takes the form of a question: "What is this?" [38,39]. The hypothesis is then tentatively connected to the qualities of the objects and a larger context by the means of definitions. In the words of Chiasson [38] (p. 12/15):

An explanatory hypothesis is a generality that enables us to begin reducing the vagueness underlying the meaning of a "surprising fact" by means of explication and demonstration (operational definition). Even if an explanatory hypothesis is incorrect, our Critical Common-sensist would still have reduced the degree of vagueness surrounding this icon by determining at least one thing that this icon is not.

Abduction so to speak keeps our eyes peeled for new information, new aspects of reality. By questioning our acritical assumptions by a retroductive (abduction combined with deduction and induction) process, we clarify the scope of our knowledge. Vagueness is not a sign of error but indicates the potential existence of previously unknown aspects of objects. Vagueness makes way for retroduction, which through hypothesis, definition and explication reduce vagueness. Vagueness can never be abolished and science has little to do with definitions. Here Peirce is in keeping with Popper (quoted in [40], p. 371), who warns against too much precision that does not reflect correctly the extent or depth of our knowledge. Explication is the job of deduction whereby the new observation or fact will be tried to be deduced from a law or theory, and thus made predictable [41,22] (p. 7,192).

\section{Forms of Knowing and Not-Knowing}

For the purposes of this paper, five main forms of knowing and not-knowing will be distinguished (Figure 1):

Figure 1. Forms of Ignorance.

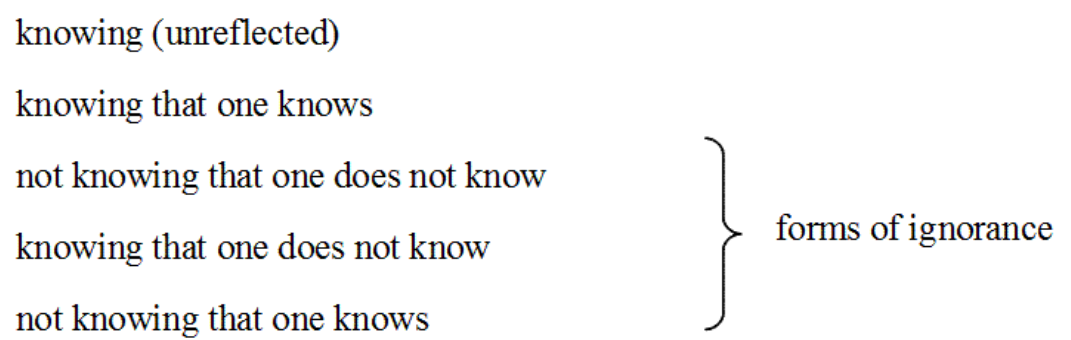


The neoclassical economic theory of decision-making has traditionally confined itself to the first and the second forms of knowing. In this paper the three forms of not-knowing-corresponding to forms of ignorance or incomplete knowledge - at the bottom of the list are of interest and will be examined in greater detail. In the following three sections the cybernetic version or versions of each form of ignorance will be presented first, and then the semiotic-pragmatic version or versions follow.

\section{Not Knowing That One Does Not Know}

\subsection{Reactive Intelligence}

Being ignorant of one's ignorance can be interpreted as an opposite of knowing caused by zero information. This strong form of ignorance suits well for the purposes of complete rationality and the early artificial intelligence movement since computers famously do not know that they do not know [11]. Computer programs are traditionally closed systems in which consequents are derived by a given set of rules from input. Put differently, there is no difference between "not knowing" versus "not knowing that one does not know”. If intelligence is seen as reactive, as it is by Rodney Brooks [42-45], the reflective or epistemic dimension of knowledge is unnecessary. Reactive intelligence posits a dyadic relation between mind (or, rather, agent) and environment, anything third-idea, thought, plan, sign, symbol-is superfluous speculation. As autonomous robots learn, bottom-up, to behave smartly in an environment without a plan or representation, there is absolutely no need to add that plan or representation to our explanations of intelligent behavior afterwards. On this view, the crucial conditions for intelligent behavior are embodiment and situatedness that enable physical interaction with the environment.

Neural networks and swarm intelligence are a step further away from intelligent behavior becauseand insofar as - they differ from Brooks' reactive systems in being disembodied. On the other hand, multi-agent systems related to the semantic web hold promise of narrowing the gap between human knowledge and machine knowledge processes in the above (i.e., reactive) respect. Distributed systems with autonomous agents negotiate and ask for pieces of information and may also ask the human user for more information (see semanticuniverse.com).

Brooks' success owes much to the openness of the system. A closed-system technology calls for different measures than an open-system technology. A nuclear plant is supposed to be kept closed, among other things, for safety reasons, whereas wind power, sun power or hybrid systems require a constant flow of elements from the environment, making openness to the environment a necessary condition of operation. In most cases there is a choice between closed- and open-system technologies, and we seem to be almost universally heading towards open-system technologies.

\subsection{Semiotic Intelligence}

Ignorance in the sense of not knowing that one does not know could be understood as a lack of questions rather than some sort of opposite of knowing [38]. Semiotic intelligence regards intelligence as an evolving, emergent phenomenon. According to Peirce [22] (pp. 2.303, 5.287), all thought is mediated by the vehicle of signs. Intelligence and awareness therefore entail signs. The activity of signs is studied by the theory of signs, called semeiotic by Peirce. In order for the world to be 
intelligible there has to be a triadic relation between the object of the world, the sign signifying the object and the respect (called the interpretant) in which the sign stands in relation to the object for somebody [46-49]. Without an interpretant the relation is only dyadic, which means that it is merely reactive, and thereby not capable of becoming at any level aware of the environment or itself. A semiotic approach to intelligence maintains that intelligence and knowledge have to be fully semiotic, that is, triadic, to qualify as intelligence or knowledge.

Following Peirce's fundamental insights, an approach called Computational Semiotics [50-53] aims at constructing triadic artificial systems, that is, systems that understand or are aware of their surroundings. A reactive system cannot achieve this because it lacks the third component, the interpretant. Semiosis is the universal mechanism by which a system intelligently connects with its environment. The system has to be a self-organizing system and the interpretants (signs or symbols) need to be grounded [54,55] in one way or another for this connection to evolve. Insofar as hybridization is possible the chance of creating genuinely semiotic intelligence should be a real one. By hybridization is meant a mixture of nature and nurture for instance in a laboratory over a long period of time by which artificial things may be rendered alive. Emmeche [23] claims that there is in principle no reason why artificial life at the level of bacteria would not be possible in the near future. However, the nature part of the mixture would make the thing synthetic rather than artificial in a traditional sense.

\section{Knowing That One Does Not Know}

\subsection{Rational Ignorance as Part of Bounded Rationality}

Knowing that one does not know is in line with what economists call rational ignorance. Rational ignorance means that if the perceived or predicted cost of acquiring information is greater than the benefit derived from the information, it is rational not to acquire the information [5]. It does not, for instance, make sense to spend two hours chasing an expected price cut of one euro, provided that one puts a price tag on one's own work time. However, the expected value is difficult or sometimes even impossible to assess. Here the theory of decision-making based on bounded rationality runs into a host of trouble. More knowledge increases uncertainty because it expands the sample, which in turn increases complexity [35].

Bryan Caplan [5] argues that in many walks of life certainty is highly valued in its own right. Politics and religion, by contrast, are areas in which individuals in the contemporary world can afford to remain ignorant as the private cost of ignorance and even irrationality are close to zero. In other words, being mistaken will not subject the individual to risks or harm: “One's belief about the relative merits of evolution and creationism is unlikely to make a difference to one's career outside of the life sciences, but maintaining that faith-healing is more effective than modern medical science may be deadly” [5] (p. 10). In some cases ignorance is truly bliss, says Caplan. Rationally ignorant agents do not draw definite conclusions whereas irrational agents do. However, when errors have practical consequences, people become increasingly rational. The search for relevant information, the use of processing power and the rational estimation of the evidence (i.e., avoiding systematic bias) require an 
incentive. When there is no incentive and error is cheap, people tend to, by sober choice, stay ignorant and even irrational.

If one is rational, insufficient information will not automatically lead to bias because one can filter "bad data” but it will lead to greater measurement error: “... agents optimize over two cognitive margins: The quantity of information they acquire, and how rationally they process the information they do have. ... The quality of an agent's estimate depends on both inputs: Less information leads to greater variance, less rationality to greater bias” [5] (p. 4). In other words, informational boundedness has or may have consequences that differ from cognitive boundedness, and therefore they should be carefully kept apart in analysis.

Rational ignorance belongs to the bounded rationality tradition. In spite of somewhat expanding the complete rationality view, bounded rationality is not an alternative to complete rationality. Bounded rationality, and rational ignorance as a part of it, are here classified under the cybernetic information conception. Gigerenzer and Todd [56] (pp. 10,11,15) remind us that, paradoxically, bounded rationality in terms of optimization under constraints can actually require more time and computational power than complete rationality. Complete rationality has to calculate all utility values of all alternatives. Bounded rationality has to first calculate all utility values of all alternatives and on top of that also calculate the benefits and costs of a continued search, including opportunity costs.

\subsection{Educated Guessing (Abduction)}

With increased knowledge also the area of what you do not know grows, as Figure 2 below illustrates:

Figure 2. Growing knowledge.
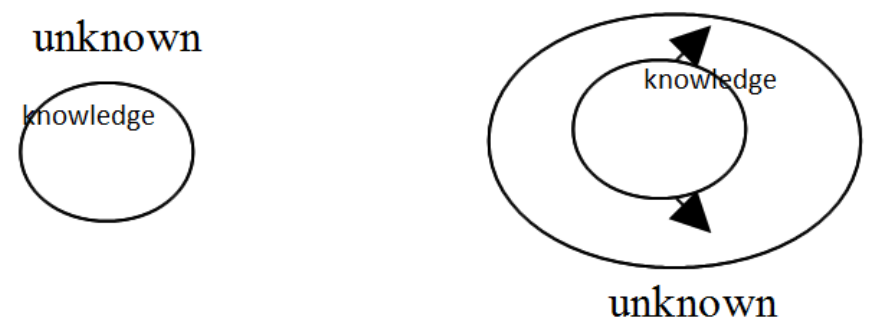

The area inside the circle on the left denotes what is known at a certain moment in time and the area outside the circle denotes the scope of what is unknown. The two concentric circles on the right illustrate that as the circle grows, the circle's line grows longer. In other words, with new answers (new knowledge) also the area of things one does not know grows bigger, meaning that new questions arise. The resultant not-knowing has a direction, that is, it is based on questions crying out for answers. This is a non-cybernetic version of knowing that one does not know.

Both abductive and deductive reasoning can be understood as vehicles of proof or explanation, in which case it can be assumed that all the information is in. Deduction, as a form of truth-preserving reasoning, arrives at truth, should the premises be true. In the case of abduction the cognitive closure (all information is in) is, by contrast, not complete but merely "presumptive", to use Gabbay and Woods' [57] terminology. Abduction is a form of ignorance-preserving reasoning. It implies that the 
abducer has, in addition to the traditional two epistemic strategies or choices of either (i) finding new information or (ii) giving up, also a third choice. The third choice (iii) is to come up with a new hypothesis, which, if true, would account for the fact. The abducer conjectures that the fact is true. What is important to pay heed to is that the abducer even now does not know fact $F$, meaning that his or her ignorance is preserved. Secondly, the universe of discourse is expanded by introducing a new element $(F)$. In this way abduction enables the reasoner to stay in touch with his or her ignorance and keep an eye on the cognitive and informational resources as they change in the course of time [57].

There must be a difference in how we see little and enough information, so that they call for different epistemic practices. This aspect of logic makes more sense if we regard it in terms of inquiry instead of explanation. Insufficient information naturally compels us to assess the epistemic value and status of our information, whereas the assumption of complete information does not. It is usually simply assumed that the data is valid. Owing to the strong empiricist legacy in science and technology, data-driven approaches are usually deemed to be more scientific than hypothesis-driven research. As a result, and as Gerd Gigerenzer [6,58] has lamented, quantitative researchers today tend to one-sidedly interpret statistics as tools for rejecting poor hypotheses or theories instead of as tools for rejecting bad data. However, both poor hypotheses and poor data are facts of scientific research - as well as of the management of any practical affairs. Both may have disastrous practical consequences. To take a recent example, Bernie Maddoff's pyramid scam would have been exposed earlier if people had trusted the data ("it is impossible to consistently make profits when the market goes down") instead of believing that there was a thought, a plan (theory) behind Maddoff's success that outsiders only did not grasp. On the other hand, no amount of good, relevant data is enough if there is no good theory behind it. The U.S. officials arguably had all the relevant data before the 9/11 incident but did not have the hypothesis of the use of a passenger air craft as a bomb [59]. A "thoughtful dissecting of data", as Chong $\mathrm{Ho} \mathrm{Yu} \mathrm{[60]} \mathrm{(p.} \mathrm{8/14)} \mathrm{calls} \mathrm{it,} \mathrm{is} \mathrm{an} \mathrm{inherent} \mathrm{part} \mathrm{of} \mathrm{quantitative} \mathrm{research,} \mathrm{and} \mathrm{it} \mathrm{cannot} \mathrm{be}$ professionally done by intuition alone or by resorting to a nil hypothesis.

\section{Not Knowing That One Knows}

\subsection{Logical-Semantic Information}

Mathematics is the strongest case of a closed system in which consequents can be deduced from a small number of simple truths called axioms. If axioms tell us everything there is, there is no need for experiments or new observations; all content is in the axioms. Theorems are derived from axioms, but axioms cannot be derived from theorems (i.e., proven by discourse) if the system in question is to qualify as axiomatic. Another option is to say that axioms are "proven" by nondiscursive means (i.e., intuition). Accordingly, Gödel claims that intellectual intuition of non-physical mathematical objects takes place by some kind of perception different from sense perception. However, different people may have differing intuitions and intuitions may change. Carlo Cellucci [10] argues that the justification of axioms by intuition is not adequate. Instead of by intuition, axioms could be justified by deriving true consequences from them, but this does not justify axioms because true consequences can be derived from false axioms. Furthermore, in axiomatic systems like mathematics (if it is an axiomatic system) axioms provide reasons for believing the consequences, not the other way round. 
The advocates of mathematics as an axiomatic system fail to present a conclusive argument for how some simple truths (axioms) could contain their logical-semantic consequences.

Another attempt at coming to terms with the phenomenon of "not knowing that one knows" is Laplace's [61] (1st edition 1819) Principle of Non-Sufficient Reason. It is one of the earliest efforts in modern times to assign ignorance a positive function in human knowledge. Many scholars were not generally impressed with Laplace's attempt, but regarded it as misguided at best and ridiculous at worst. John Maynard Keynes [62] (p. 176) says:

What was required was not a wide experience or detailed information, but a completeness of symmetry in the little information there might be. It seemed to follow from the Laplacean doctrine that the primary qualification for one who would be well informed was an equally balanced ignorance.

Keynes sees little value in Laplace's principle, but those empiricists who assume complete knowledge, he adds, do not fare any better because the assumption of complete knowledge renders probability calculations futile.

The problems that a mathematical interpretation of a Laplacean balanced ignorance leads to is illustrated by Richard Whately's Elements of Logic, first published in 1826 [63] (p. 139) [64]. In his example of convergent probabilities in favor of a certain book having been written by a certain author, say Bacon, Whately reverses the part-probabilities, initially 6/35 in favor of the conclusion, so that the chances against the very same conclusion (after the reversal being 12/35) eventually leads to 23/35 in favor of the conclusion that the book is written by Bacon. This is clearly absurd. There seems to be an additional premise smuggled in which has not previously made any appearance in the calculation. The hidden premise is that a lack of evidence indicates that no such evidence is likely to be coming forward, which makes the universe of discourse systematically skewed in a certain way. Whately's practical variant of convergent probabilities gives an inkling that the general idea behind the mathematical variant of convergent probabilities is not completely mad. We have had to wait until very recently for Gerd Gigerenzer to find out in what way, and to what extent, the allusive intuition of a balanced ignorance, as an aid to knowing, is reasonable (discussed under the rubric of Ecological rationality below).

\subsection{The Analytical Method and Inferentialism}

Neither intuition nor deduction of consequences from given axioms have a satisfactory answer to how axioms are justified and discovered. Carlo Cellucci [10,65] makes the bold suggestion that the axiomatic method is a subordinate part of the analytic one. Consequently, axioms (principles, starting points, premises) are discovered by the analytic method (deriving axioms from consequences) not by the axiomatic method. The analytic procedure is the following: Assume a hypothesis that seems best (seems to lead to true consequences) and then assume another hypothesis that seems to support the earlier hypothesis, ad infinitum (as described by Hippocrates of Chios and Plato). The hypothesis is derived from the problem (and possibly other data) non-deductively. Investigation of the plausibility (by comparing reasons for and against) of a hypothesis may bring new knowledge to light. Reasons are generally compared in view of their consequences, and old hypotheses may have to be dropped in the 
light of new knowledge. The analytic method is thus both a method of discovery and justification. Because one can by non-deductive inferences from the same premises draw different conclusions it is important to carefully choose conclusions. Drawing different conclusions from the very same premises does not lead to chaos because there are good and bad reasons for drawing a given conclusion. Science starts from, or is based on, accepted opinions that can be justified inferentially (i.e., by non-deductive and deductive means) rather than justified by the internal logical structure of inferences, that is, formally justified.

Robert Brandom's [66] inferentialism is a form of conceptual pragmatism that studies knowing (believing, saying) that in terms of knowing how to do something. By comparison, formalist approaches identify logic with formally valid inferences, assuming that statements are made logical by adding suppressed premises and completing enthymemes. A good inference thus depends on the truth of conditionals: If "Lightning", then "Thunder". Formalists do not recognize materially correct inferences: Only form matters, not content. Nevertheless, concept-using creatures differ from non-concept-using ones by their inferential articulation, i.e., the giving and asking for reasons. Expressing something is to make it capable of serving as both premise and conclusion in inferences (note the analytic cycle!). Saying or grasping a concept is mastering its inferential use (a sort of knowing how), and truth is what is preserved by good inferences. Hence inferentialism starts with a practical distinction between good and bad inferences.

Logic studies inferences. Explicit expressions have implicit inferential consequences (e.g., "red cloth" implies that it is colored). Mastering meaning is mastering the (explicit and implicit) inferential connections of expressions and concepts, i.e., knowing what follows or not from them and what is evidence for them or not. The material proprieties of inference, involving non-logical vocabulary, are primary and used for explaining the formal proprieties of inference. The contents of the claims matter to the goodness of reasoning. Consequently, rationality is not a purely logical capacity (especially not in the sense of formally valid inferences). Logic is thus not a canon of right reasoning but a tool for making explicit our inferential commitments (i.e., clarifying all conceptual content) [66]. On this view, "not knowing that one knows" is fundamentally a discursive (analytic) enterprise primarily based on everyday language.

\subsection{Ecological Rationality (Gut Feelings)}

Gerd Gigerenzer and his colleagues $[67,68]$ have founded a research program that they call Fast and Frugal Heuristics. The program studies ecological rationality, by which is meant intelligence as adaptation to the environment. It should not be confused with the Heuristics and Biases program [69] which accepts the overall conception of rationality of the complete rationality approach and a cybernetic view on information. The program of Fast and Frugal Heuristics does not. Gigerenzer's program has succeeded in showing that Laplace's aspirations to render ignorance a positive effect on our knowledge are in some cases viable. The simplest case of this is the recognition heuristic. When given the task of picking out from a list of German cities those cities that have over 100,000 inhabitants, people tend to choose cities which they recognize. The mere recognition is a cue that indicates that the city is a big one. The best result is achieved when half the cities on the list are not recognized and the other half is. What is surprising is that this sort of half ignorance gives a better result than "full knowledge". In tests people 
from Germany, who know or recognize all the cities, score worse than people from the U.S. who know less than all, ideally a half of the cities [56] (pp. 44,45) and [6] (p. 192).

In order to succeed in explaining balanced ignorance or not-knowing-that-one-knows one will have had to let go of the assumption of a thinking head, that is, the assumption of an acontextual, monolithic, disembodied knowledge. An example of a cognitive decision algorithm is how professionals can sort newly born chicks according to their sex with a very high rate of accuracy without being able to say how they do it and what their decision is based on. This is clearly a case of not knowing that one knows. Fast and frugal heuristics are typically unconscious aids to decisions or inferences, that is, gut feelings. They are based on individual, social or evolutionary learning. The above example is a case of individual learning.

Landa [70] points out how for instance the classification of people into those with whom one should, and those with whom one should not, enter into business relations, functions as a heuristic that economizes on scarce information. When these classifications are institutionalized, they can play the role of a heuristic or decision-making aid, cutting down the cost of information search. This is a case of an induction-based elimination, which is neither based on individual learning nor innate, but based on social institutions. Landa's example illustrates how information can be outsourced into social structures and practices, and how it can be elicited in the appropriate social context. Let it be said in passing that Zeleny [4] (p. 178) is right in saying that in the new economy "trust, as knowledge, has become a form of capital”.

Examples of innate inductive elimination are those fast and frugal heuristics [71] that are instinctive in humans or other animals and all of those that are programmed by evolution to such a degree that they leave virtually no room for reinterpretation (i.e., they are in a sense dyadic). For instance, the instinctive abhorrence of incest narrows down the choices for a spouse. The example illustrates that biologically determined information structures function as heuristic devices, shaping the mind (rather, the mind-body) part of the mind-environment fit.

\section{Conceptualizations of Information: A Summary}

Figure 3 below schematically sums up the variety of concepts of information related to knowing and ignorance that have come up in the discussion so far.

The classification of information conceptualizations comes directly from the examples of various approaches to information and ignorance presented until now. The labels cybernetic and semiotic-pragmatic stand for a rough division between two basic approaches to information. Rather than accentuating the continuity between cybernetic and later biologically inspired systemic thought, as François [72] does, this paper has concentrated upon differences between two classes of information philosophies. Moreover, the continuity-view implicitly assumes cybernetics to be the mother of all systemic thinking, which assumption is historically incorrect. The second lowest level in Figure 3 indicates various conceptions of forms of rationality or intelligence. The lowest level presents different methods of information elicitation or/and sources of information in case there are more than one. Let it be said in passing that the rather odd label 'informational' refers to Section 9.1 that deals with rational ignorance as part of bounded rationality. Hence, the approach generally falls under a bounded rationality approach to information. The point is that informational boundedness does not necessarily 
imply cognitive boundedness, thus revealing an aspect of knowing-that-one-does-not-know which has escaped the earlier bounded rationality approach.

Figure 3. Various conceptualizations of information.

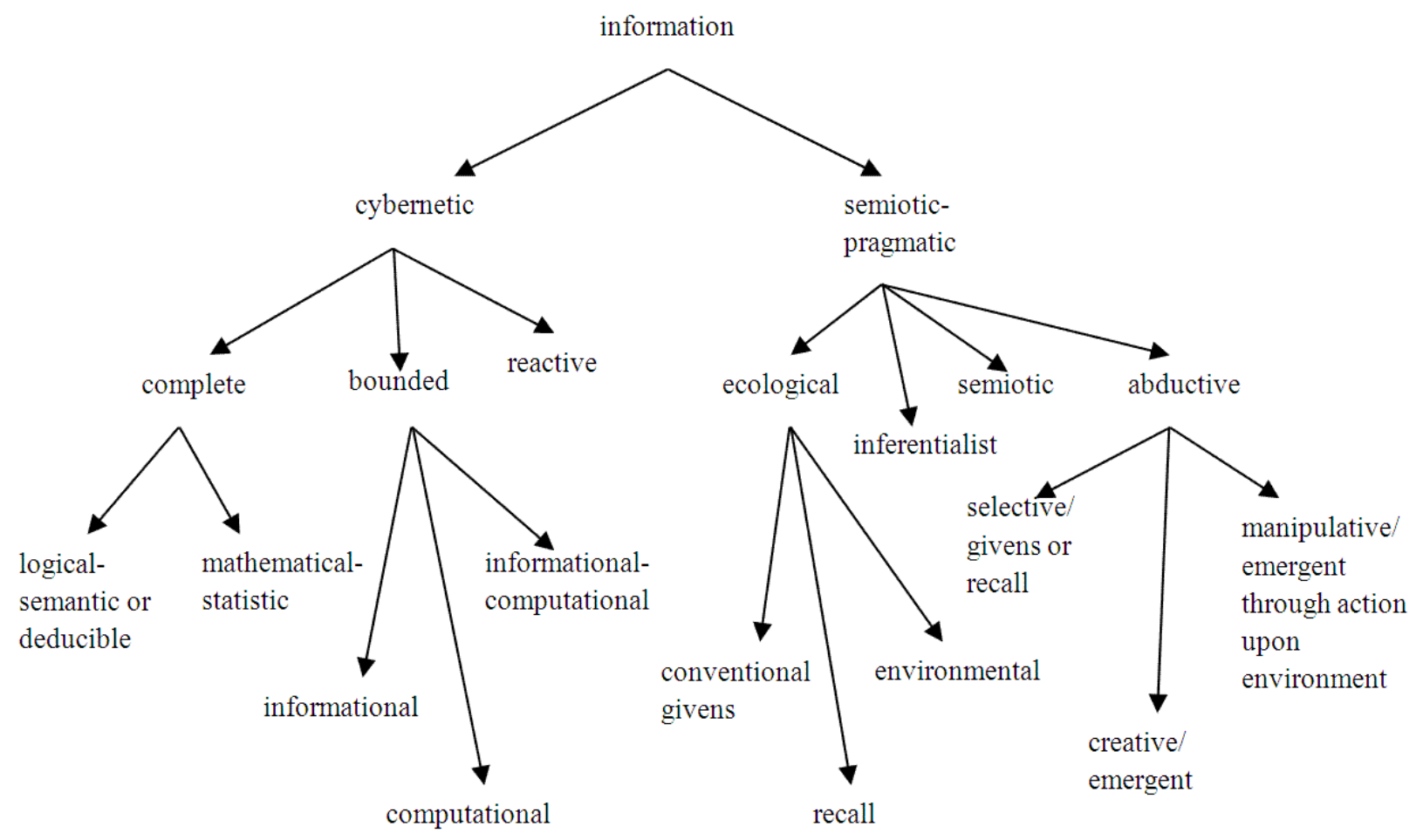

Generally speaking, the cybernetic approach—with the exception of Shannon's approach—takes a proof-oriented view on information whereas the semiotic-pragmatic approach takes a more dynamic, inquiry-oriented view on information. The reactive intelligence is in this paper placed under the rubric cybernetic approach in spite of a number of features that would enable it being classed in the other category. Especially the dynamic, evolving interaction with the environment suggests that it should be placed under the semiotic-pragmatic approach. Namely, the semiotic-pragmatic view assumes that information is elicited through some sort of encounter. However, in reactive intelligence, the interaction with the environment is causal-mechanistic. In order for it to be considered intelligent in a semiotic-pragmatic sense it would have to include some sort of teleological principle (final cause). In addition to causality, another metaphysical disagreement which separates the cybernetic approach from the semiotic-pragmatic one is determinism versus indeterminism, respectively.

\section{Conclusion}

Information can be conceptualized in a variety of ways. The cybernetic view is not the only right one. At least two general, complementary and, at times, opposing views on information and knowing, can be distinguished: The cybernetic and the semiotic-pragmatic. The traditional gap between these two approaches has led to misunderstanding and confusion. Far from being a complete and detailed mapping of informations, the present paper suggests that some well-documented but generally poorly understood phenomena of incomplete knowing are connected to different modes of being of information. 
Within certain frameworks or from certain perspectives, the cybernetic and computational views on information make perfect sense. So do the semiotic-pragmatic ones. Consequently, what we have here is an embarrassment of riches (overabundance). The excessive, incompatible parts can be cleared out of sight by employing strict definitions. However, if the excess is real, definitions may function as blinkers, covering from sight everything that is of interest to future research, but not yet within grasp. As was mentioned earlier, definitions need to accurately reflect the depth and breadth of our knowledge in order to be of assistance. Stressing the role of definitions, and proceeding by immaculate logical steps from axioms to theorems is one way, or rather, one part, of doing science. It is also possible to start with (surprising) facts and figure out what kind of hypotheses or theories would be called for to explain them. The latter is known as an abductive method, especially suitable for cases with an embarrassment of riches. Both aforementioned ways of doing science are legitimate and viable. The information science seems to be in a stage of development which could benefit from the abductive approach, which is applied in this paper. To repeat: Both ways to knowledge or true belief are legitimate. Feel free to take this paper as a challenge to make better computational sense of ignorance than has been done so far.

\section{Acknowledgements}

Thanks to Francisco Augusto Alcaraz Garcia for drawing my attention to one important piece of the puzzle and Milan Zeleny for forcing me to take a closer look at the puzzle of information in the first place. Also, Mark Burgin, the editor, was very helpful and supportive.

\section{References}

1. Zeleny, M. Management Support Systems: Towards Integrated Knowledge Management. Hum. Syst. Manage. 1987, 7, 59-70.

2. Floridi, L. Trends in the philosophy of information. In Handbook of the Philosophy of Information; van Benthem, J., Adriaans, P., Eds.; Elsevier: Amsterdam, the Netherlands, 2008; pp. 113-131.

3. Hatchuel, A. Towards design theory and expandable rationality: The unfinished program of Herbert Simon. J. Manage. Gov. 2002, 5, 260-273.

4. Zeleny, M. Human Systems Management: Integrating Knowledge, Management and Systems; World Scientific: Hackensack, NJ, USA, 2005.

5. Caplan, B. Rational ignorance versus rational irrationality. Kyklos 2001, 54, 3-26.

6. Gigerenzer, G. Adaptive Thinking. Rationality in the Real World; Oxford University Press: New York, NY, USA, 2000.

7. Shannon, C.E. A Mathematical Theory of Communication. Bell Syst. Tech. J. 1948, 27, 379-423, 623-656.

8. Shannon, C.E.; Weaver, W. The Mathematical Theory of Communication; University of Illinois Press: Urbana, IL, USA, 1963.

9. Wiener, N. Cybernetics or Control and Communication in the Animal and the Machine; Wiley: New York, NY, USA, 1961. 
10. Cellucci, C. Mathematical discourse vs mathematical intuition. In Mathematical Reasoning and Heuristics; Cellucci, C., Gillies, D., Eds.; College Publications: London, UK, 2005; pp. 137-165.

11. Gärdenfors, P. Blotta Tanken; Bokförlaget Nya Doxa: Falun, Sweden, 1992.

12. Zins, C. Conceptual approaches for defining data, information, and knowledge. J. Am. Soc. Inf. Sci. Technol. 2007, 58, 479-493.

13. Zeleny, M. Autopoiesis (self-production) in SME networks. Hum. Syst. Manage. 2001, 20, 201-207.

14. Galison, P. The Ontology of the Enemy: Norbert Wiener and the Cybernetic Vision. Crit. Inquiry 1994, 21, 228-266.

15. Tuomi, I. Data is More Than Knowledge: Implications of the Reversed Hierarchy for Knowledge Management and Organizational Memory. In Proceedings of the Thirty-Second Hawaii International Conference on Systems Sciences, Maui, HI, USA, 1999; IEEE Computer Society Press: Los Alamitos, CA, USA, 1999.

16. Boisot, M.; Canals, A. Data, Information, and Knowledge: Have We Got It Right? J. Evol. Econ. 2004, 14, 1-25.

17. Burgin, M. Theory of Information: Fundamentality, Diversity and Unification; World Scientific Publishing Company: Singapore, 2010.

18. Patokorpi, E.; Ahvenainen, M. Developing an Abduction-Based Method for Futures Research. Futures 2009, 41, 126-139.

19. Patokorpi, E. Situated, embodied cognition and its implications for knowledge mobilisation design. Electron. J. Knowledge Manage. 2009, 7, 367-376.

20. Alavi, M.; Leidner, D.E. Review: Knowledge management and knowledge management systems: Conceptual foundations and research issues. MIS Q. 2001, 25, 107-136.

21. Dourish, P. Seeking a Foundation for Context-Aware Computing. Hum. Comput. Interact. 2001, 16, 2-4.

22. Peirce, C.S. Collected Papers of Charles Sanders Peirce; Hartshorne, C., Weiss, P., Eds.; Belknap Press of Harvard University: Cambridge, MA, USA, 1934-1963.

23. Emmeche, C. A-life, Organism and Body: the semiotics of emergent levels. In Proceedings of Ninth International Conference on the Simulation and Synthesis of Living Systems, Boston, MA, USA, 2004; Husbands, M., Hutton, P., Kumar, T., Suzuki, S., Bedeau, H., Eds.; Alife IX: Boston, MA, USA, 2004; pp. 117-124.

24. Baas, N.A.; Emmeche, C. Emergence and explanation. SFI Working Paper 97-02-008; Santa Fe Institute: New Mexico, NW, USA, 1997; pp. 67-83.

25. Floridi, L. Is Semantic Information Meaningful Data? Philos. Phenomen. Res. 2005, 70, 351-370.

26. Floridi, L. The Philosophy of Information and Its Problems, 2005. http://www.philosophy ofinformation.net/publications/pdf/lfdieisp.pdf. (Accessed on 17 Jaunary, 2011)

27. Burgin, M. Data, Information, and Knowledge. Information 2004, 7, 47-57.

28. Magnani, L. Model-Based and Manipulative Abduction in Science. Found. Sci. 2004, 9, 219-247.

29. Magnani, L. Reasoning through doing. Epistemic mediators in scientific discovery. J. Appl. Log. 2004, 2, 439-450.

30. Simon, H.A. Models of Man; Wiley: New York, NY, USA, 1957.

31. Ashby, W.R. An Introduction to Cybernetics; Chapman \& Hall Ltd.: London, UK, 1957.

32. Weick, K.E. Sensemaking in Organizations; Sage: Thousand Oaks, CA, USA, 1995. 
33. Bynum, T.W. Norbert Wiener's vision: The impact of the "automatic age” on Our Moral Lives. In The Impact of the Internet on Our Moral Lives; Cavalier, R., Ed.; State University of New York Press: New York, NY, USA, 2005; pp. 11-25.

34. Scott, J. Rational Choice Theory. In Understanding Contemporary Society: Theories of the Present; Browning, G., Halcli, A., Hewlett, N., Webster, F., Eds.; Sage: London, UK, 2000.

35. Congleton, R.D. In Defense of Ignorance. East. J. Econ. 2001, 27, 391-408.

36. Bertilsson, T.M. Towards a Social Reconstruction of Science Theory. Peirce's Theory of Inquiry, and Beyond; Bokcafeet: Lund, Sweden, 1978.

37. Coppock, P.J. A semiotic perspective on the development of (artificial) consciousness. In Proceedings of the Fifth Nordic Conference in Artificial Intelligence, Trondheim, Norway, 29-31 May, 1995; Aamodt, A., Komorowski, J., Eds.; IOS Press: Amsterdam, The Netherlands, 1995; pp. 378-386.

38. Chiasson, P. Abduction as an Aspect of Retroduction. Semiotica 2005, 153, 223-242.

39. Zhou, W. The Role of Metacognition in Abduction: A Goal Theoretical Perspective, 2004. http://cognitio.uqam.ca/2004/zhou.pdf. (Accessed on 17 January , 2011).

40. Klaes, M. Evolutionary Economics: In Defence of Vagueness. J. Econ. Method 2004, 11, 359-376.

41. Chauviré, C. Peirce, Popper, abduction and the idea of a logic of discovery. Semiotica 2005, 153, 209-221.

42. Brooks, R.A. Intelligence without reason. In Proceedings of the Twelfth International Joint Conference on Artificial Intelligence, Sydney, Australia, 1991; IJCAI-91: Sydney, Australia, 1991; pp. 569-595.

43. Brooks, R.A. Intelligence without representation. Artif. Intell. 1991, 47, 139-159.

44. Kelemen, J. A View of Rationality at the End of the Modern Age. Hum. Affairs 1998, 8, 101-111.

45. Kelemen, J. The Agent Paradigm. Comput. Inf. 2003, 22, 513-519.

46. Eco, U. Horns, Hooves, Insteps. In The Sign of Three; Eco, U., Sebeok, T.A., Eds.; Indiana University Press: Bloomington, Indiana, 1983; pp. 199-219.

47. Bertilsson, T.M. The Elementary Forms of Pragmatism: On Different Types of Abduction. Eur. J. Soc. Theory 2004, 7, 371-389.

48. Wirth, U. Abduktion und ihre Anwendungen. Zeitschrift für Semiotik 1995, 17, 405-424.

49. Kruijff, G.J.M. Peirce's late theory of abduction: A comprehensive account. Semiotica 2005, 153, 431-454.

50. Fetzer, J. Mental Models: Reasoning without Rules. Minds Mach. 1999, 9, 119-125.

51. Gudwin, R.; Queiroz, J. Towards an Introduction to Computational Semiotics. In Proceedings of the International Conference on Integration of Knowledge Intensive Multi-Agent Systems, Boston, MA, USA, April 18-21, 2005; Thompson, C., Hexmoor, H., Eds.; IEEE Systems, Man and Cybernetic Society: Waltham, MA, USA, 2005; pp. 393-398.

52. Nadin, M. Semiotic Machine. Public J. Semiotics 2007, 1, 57-75.

53. Pospelov, D.A. Semiotic models in artificial intelligence problems, 1975. http://citeseerx.ist. psu.edu/viewdoc/download?doi=10.1.1.76.5993\&rep=rep1\&type=pdf (Accessed on 7 February, 2009).

54. Barsalou, L.W. Cognitive and neural contributions to understanding the conceptual system. Curr. Dir. Psychol. Sci. 2008, 17, 91-95. 
55. Barsalou, L.W. Grounded cognition. Annu. Rev. Psychol. 2008, 59, 617-645.

56. Gigerenzer, G.; Todd, P.M. Simple Heuristics That Make Us Smart. Oxford University Press: New York, NY, USA, 1999.

57. Gabbay, D.M.; Woods, J. Advice on Abductive Logic. Log. J. IGPL 2006, 14, 189-219.

58. Anderson, D.R. Some background on why people in the empirical sciences may want to better understand the information-theoretic methods, 2003. http://www.jyu.fi/science/laitokset/bioenv /en/coeevolution/events/itms/why (Accessed on January 6, 2009).

59. Keen, P.G.W. Knowlewdge mobilization: The challenge for information professionals. In Proceedings of the Asia Pacific Conference on Library \& Information Education \& Practice; Khoo, C., Singh, D., Chaudhry, A.S., Eds.; A-LIEP 2006: Nanyang, Singapore, 2006; pp. 1-9.

60. Yu, C.H. Is There a Logic of Exploratory Data Analysis? 1994. http://www.creative-wisdom.com/ pub/Peirce/Logic_of_EDA.html (Accessed on November 2, 2009).

61. Laplace, P.S. A Philosophical Essay on Probabilities, 6th ed.; Truscott, F.W., Emory, F.L., Jr., Eds.; Chapman \& Hall: London, UK, 1902.

62. Keynes, J.M. A Treatise on Probability; MacMillan \& Co. Ltd: London, UK, 1963.

63. Whately, R. The Elements of Logic; Longmans, Green, and Co.: London, UK, 1882.

64. Patokorpi, E. Rhetoric, Argumentative and Divine; Peter Lang Verlag: Frankfurt, Germany, 1996.

65. Cellucci, C. The scope of logic: Deduction, abduction, analogy. Theoria 1998, 64, 217-242.

66. Brandom, R.B. Articulating Reasons. An Introduction to Inferentialism; Harvard University Press: Cambridge, MA, USA, 2000.

67. Todd, P.M.; Gigerenzer, G. Environments that make us smart: Ecological rationality. Curr. Dir. Psychol. Sci. 2007, 16, 167-171.

68. Gigerenzer, G.; Hoffrage, U.; Goldstein, D.G. Fast and Frugal Heuristics Are Plausible Models of Cognition: Reply to Dougherty, Franco-Watkins, and Thomas. Psychol. Rev. 2008, 115, 230-239.

69. Kahneman, D. A Perspective on Judgment and Choice; Mapping Bounded Rationality. Am. Psychol. 2003, 58, 697-720.

70. Landa, J.T. Bounded rationality of Homo Classificus: The law and bioeconomics of social norms as classification. Chic. Kent Law Rev. 2005, 80, 1167-1180.

71. Gigerenzer, G.; Goldstein, D.G. Reasoning the fast and frugal way: Models of bounded rationality. Psychol. Rev. 1996, 103, 650-669.

72. François, C. Systemics and cybernetics in a historical prespective. Syst. Res. Behav. Sci. 1999, 16, 203-219.

(C) 2011 by the authors; licensee MDPI, Basel, Switzerland. This article is an open access article distributed under the terms and conditions of the Creative Commons Attribution license (http://creativecommons.org/licenses/by/3.0/). 